\title{
Entrepreneurship
}

Jul a Dez $2019-$ v.3 - n.2

ISSN: 2595-4318

This article is also available online at: www.sustenere.co

\section{Responsabilidade socioambiental: um relato sobre o incentivo ao engajamento socioambiental em instituição de ensino superior em Caucaia/CE}

O presente trabalho objetiva a relatar as contribuições de um projeto de responsabilidade socioambiental em uma Instituição de Ensino Superior a partir da experiência colaborativa de um profissional. Dentro deste contexto de modo específico: identificar a necessidade de projetos socioambientais para a imagem institucional perante a sociedade civil; Citar as principais ações e investimentos realizados em um Projeto de Responsabilidade Socioambiental; e Relatar as limitações percebidas na visão do profissional atuante no projeto. Diante disso, visa-se responder o seguinte questionamento: Que benefícios podem ser relatados em uma IES, pelo seu engajamento e dos seus alunos em Projetos de Responsabilidade Socioambiental - PRS?. Assim, tomou-se como metodologia para coleta e avaliação dos resultados, um relato de experiência por meio de entrevista pautada em questionário estruturado, aplicado a Coordenadora de Extensão de uma instituição de ensino superior de Caucaia/CE. Desse modo, foi possível obter a percepção da idealizadora do projeto, a qual evidenciou os benefícios obtidos com a implantação do projeto envolvendo o bem estar e a educação ambiental dos alunos engajados e da sociedade civil assistenciada.

Palavras-chave: Ensino e aprendizagem; Sustentabilidade; Responsabilidade socioambiental.

\section{Social and environmental responsibility: a report on encouraging social environmental engagement in higher education institution in Caucaia/CE}

This paper aims to report the contributions of an environmental responsibility project in a Higher Education Institution based on the collaborative experience of a professional. Within this specific context Identify the need for socio-environmental projects for the institutional image before civil society; To cite the main actions and investments made in a Social and Environmental Responsibility Project; And report the limitations perceived in the vision of the professional involved in the project. In view of this, it is intended to answer the following question: 'What benefits can be reported in an HEl, through its engagement and its students in Social and Environmental Responsibility Projects - PRS?' Thus, it was used as methodology for the collection and evaluation of results, an experience report through a structured questionnaire interview, applied to the Extension Coordinator of a Caucaia/CE college. In this way, it was possible to obtain the perception of the idealizer of the project, which showed the benefits obtained with the implementation of the project involving the welfare and the environmental education of the students engaged and the civil society assisted.

Keywords: Teaching and learning; Sustainability; Institutions of Higher Education.

Topic: Planejamento, Estratégia e Competitividade

Reviewed anonymously in the process of blind peer.
Received: $14 / 07 / 2019$

Approved: $27 / 11 / 2019$
João Luis Josino Soares

Faculdade Terra Nordeste, Brasil

http://lattes.cnpq.br/4714394538597175

joaojosino@hotmail.com

Salviano José de Oliveira Filho

Faculdade de Tecnologia do Nordeste, Brasil

http://lattes.cnpq.br/9727485203928628

salviano.filho@fatene.edu.br
Referencing this:

SOARES, J. L. J.; OLIVEIRA FILHO, S. J.. Responsabilidade socioambiental: um relato sobre o incentivo ao engajamento socioambiental em instituição de ensino superior em Caucaia/CE. Entrepreneurship, v.3, n.2, p.13-18, 2019. DOI:

http://doi.org/10.6008/CBPC2595-4318.2019.002.0002 


\section{INTRODUÇÃO}

A formação acadêmica pode estar ligada ao desempenho do professor em sala de aula, como multiplicador do conhecimento e agente responsável pela absorção do ensino para com seus alunos. Para Vasconcelos (1996), a figura do educador ensino superior está representada pela sua relação com o corpo discente, ao afirmar que relacionar teoria e prática é fator de garantia de competência para o exercício do magistério universitário. $O$ processo de ensino-aprendizagem se baseia numa relação estabelecida entre professor e aluno que pressupõe uma preocupação do primeiro com o efetivo aprendizado por parte do segundo.

Isso não poderia ser diferente, ao inserir na formação superior o ensino da ética, cidadania e responsabilidade social, como mecanismo de desenvolvimento humano e profissional dos alunos. Nesse sentido, entende-se que os principais agentes integrantes da formação acadêmica são: as Instituições de Ensino Superior - IES, que abrigam as faculdades e os insumos necessários para que sejam ministradas as aulas; os professores, responsáveis por ministrar essas aulas, disseminando o saber; e os alunos, que recebem os ensinamentos transmitidos pelos professores e usufruem da estrutura oferecida pela IES para desenvolverem melhor o aprendizado. Pautando-se nesses princípios, evidencia-se que os três agentes citados acima são mutuamente dependentes, pois necessitam uns dos outros para cumprir seu papel, seja como educador ou educando, e são fundamentais para completar a estrutura educacional.

É claro que para o serviço ensino seja eficaz, é necessário que o aluno tenha também consciência que não depende exclusivamente do professor, para que ele consiga se tornar um bom profissional após sua formação acadêmica, uma vez que, de nada adiantaria se o professor possuísse os melhores recursos para ministrar suas aulas e tivesse as melhores qualificações para ocupar o cargo docente, se o aluno não possuir interesse pelo conteúdo exposto e não buscar outras formas pertinentes de conhecimento, além do recebido em sala de aula. Então, a partir dessas percepções, levantou-se a seguinte questão: Que benefícios podem ser relatados em uma IES, pelo seu engajamento e dos seus alunos em Projetos de Responsabilidade Socioambiental - PRS?

Mediante a essa problemática, toma-se como objetivo geral, relatar as contribuições de um projeto de responsabilidade socioambiental em uma IES a partir da experiência colaborativa de um profissional. De forma específica, buscou-se: Identificar a necessidade de projetos socioambientais para a imagem institucional perante a sociedade civil; Citar as principais ações e investimentos realizados em um PRS; E relatar as limitações percebidas na visão do profissional atuante no projeto.

Com isso, justifica-se que a valorização do ensino parte da integração entre o grau de interesse do aluno e o conteúdo explanado em sala de aula, é um diferencial para se agregar outras culturas no decorrer de seu processo de aprendizagem. Metodologicamente, vê-se no presente relato de experiência o interesse de utilizar como objeto de estudo, a agregação de valor a prática da disciplina de Responsabilidade Socioambiental em uma IES localizada e Caucaia/CE, uma vez que esta passou a desenvolver o engajamento de seus alunos em um projeto social de educação ambiental e convívio social no Parque Botânico daquele 
município, um equipamento público ainda pouco divulgado e ocupado pela população local, antes da intervenção proposta e posteriormente realizada pela instituição aqui relatada.

Para tanto, o presente estudo, fez-se na modalidade de Relato de Experiência, iniciado com a realização de uma pesquisa qualitativa aplicada em entrevista, pautada em um questionário estruturado, o qual foi dotado de 07 perguntas abertas em 16 de outubro de 2018, para a coleta do depoimento da Coordenadora de Extensão, da IES aqui estudada.

\title{
DISCUSSÃO TEÓRICA
}

\section{Responsabilidade Socioambiental nas IES}

É importante frisar que, a responsabilidade social ambiental nas IES não deve ser vista como mera obrigação legal, ou uma disciplina inserida na matriz curricular por necessidade impositiva. É necessário estabelecer um amplo debate que ultrapasse o ambiente acadêmico e se dissemine pela sociedade civil, para que esta seja agente de colaboração e perpetuação de um mundo ecologicamente sustentável. Diante disso, é importante citar Dias Sobrinho (2005) o qual relata que o sentido essencial da responsabilidade social da Educação Superior consiste em produzir e socializar conhecimento que tenha não só mérito científico, mas também valor social e formativo. Para Caixeta et al. (2013):

\begin{abstract}
Ao explicitar que a Educação Superior é responsável por formar profissionais comprometidos com o meio social em que estão inseridos, a LDB (1996) aponta para a responsabilidade social das instituições que a concretizam, uma vez que esse meio social extrapola o contexto da IES e se estende para o conjunto de pessoas, recursos naturais e instrumentais, sejam eles tecnológicos ou não, que compõem o espaço de vida e de ação dessas pessoas. Espaços onde os estudantes e os demais membros da comunidade acadêmica, orientados teórica e metodologicamente, atuam na gestão e prática de projetos com vistas à promoção do outro e da sociedade, mas, também, de si mesmos nesse processo.
\end{abstract}

Assim, é visível na fala dos autores citados que a responsabilidade social se estabelece por meio da formação cidadã, numa fusão entre a formação acadêmica, profissional e o senso comum ainda sendo fator de produção do conhecimento, o que representa um desafio para se prevalecer o senso crítico, formador do agente de transformação social e ecologicamente sustentável.

\section{Marketing Ambiental e Sustentabilidade}

Nos últimos anos, o debate sobre a preservação do meio ambiente tem ganhado cada vez mais força e espaço na mídia, principalmente com a indiscutível expansão industrial e sociedade de consumo, advento da produção em massa, o que ampliou os danos ao meio ambiente consequentemente. Dessa forma, evidenciou-se a exploração dos recursos ambientais para a produção, com objetivo de formar mercados consumidores cada vez maiores. Vale ressaltar ainda que o crescimento populacional contribui para uma maior demanda nos meios de produção e atingimento das fontes renováveis, com o aumento da poluição, principalmente gerada pela emissão de gases nocivos, efeito estufa e o aquecimento global. Nesse contexto, frisa-se a afirmação de Boone et al. (2001), ao exporem que:

O marketing verde, conhecido também como marketing ambiental ou marketing ecológico, 
é uma modalidade derivada do marketing básico o qual visa atender às necessidades daqueles clientes que possuem um comportamento diferenciado por se preocuparem com medidas sustentáveis e com danos à natureza. Consiste na aplicação da promoção, produção e também na recuperação de produtos que são ecológicos e sensíveis ao meio ambiente.

Sendo assim, surgiu a preocupação e a necessidade de mudanças nas atitudes tanto no mercado produtivo quanto no mercado consumidor, e assim, as iniciativas organizacionais para comunicar a sociedade uma preocupação com a manutenção do seu bem-estar e projeção de uma postura 'ecologicamente correta' para agregar valor à sua imagem, tornou-se mais ampla e comum atualmente.

\section{Ensino e Aprendizagem}

É claro que para o serviço ensino seja eficaz, é necessário que o aluno tenha também consciência que não depende exclusivamente do professor, para que ele consiga se tornar um bom profissional após sua formação acadêmica, uma vez que, de nada adiantaria se o professor possuísse os melhores recursos para ministrar suas aulas e tivesse as melhores qualificações para ocupar o cargo docente, se o aluno não possuir interesse pelo conteúdo exposto e não buscar outras formas pertinentes de conhecimento, além do recebido em sala de aula.

Vale reforçar que na concepção de Vasconcelos et al. (1996) que assinala que "o professor que consegue aliar seu conhecimento teórico à prática profissional atualizada, com certeza estará prestando um melhor serviço a seus alunos". Nesse sentido, a valorização do ensino parte da integração entre o grau de interesse do aluno e o conteúdo explanado em sala de aula, a fim de agregar outras culturas no decorrer de seu processo de aprendizagem.

\section{Relato de Experiência}

Dada a entrevista efetuada junto a Coordenação de Extensão de uma IES de Caucaia/CE, conforme mencionada na introdução desde estudo, relata-se a seguir, no Quadro 1, as indagações e pontos de vista da pesquisa:

Quadro 1: Entrevista aplicada Pergunta 1 - Quais os Projetos de Responsabilidade Socioambiental Desenvolvidos na Instituição de Ensino?

'Não há apenas um projeto socioambiental na instituição. Há o projeto Viva a Natureza que acontece no Parque Botânico de Caucaia, aos domingos, em parceria com a prefeitura do município. É um projeto de conscientização social, através do lazer, bemestar, contato e respeito à natureza. E o outro projeto são as semanas acadêmicas semestrais desenvolvidas na faculdade, atreladas a disciplina de Responsabilidade Socioambiental, onde os alunos apresentam por meio de exposição científica os projetos sociais e ambientais desenvolvidos pelas empresas por eles visitadas. Existem pelo menos três outros projetos sociais desenvolvidos na instituição com base no incentivo a prática esportiva e bem estar, que não estão sob a minha coordenação. Um deles voltado para crianças, buscando ocupar o tempo livre desses menores, evitando que ingressem ou permaneçam na criminalidade. Há um outro projeto para pessoas com deficiência, incentivando a prática de natação. Contamos também com um projeto que promove o Treinamento Funcional, Voleibol, Defesa Pessoal, Natação, Yoga, dentre outros esportes, aberto ao público adulto da comunidade e colaboradores da instituição. E temos ainda um projeto que promove encontros mensais entre doulas $\mathrm{e}$ mulheres grávidas da comunidade.'

Pergunta 2 - Quando iniciaram os projetos e como foi percebida necessidade de ações socioambientais nesta IES?

'Quando passei a ministrar a disciplina de Responsabilidade Socioambiental percebi que haviam ações isoladas que poderiam ser melhor organizadas. Então em reunião com as coordenações de curso e gestão institucional, fui convidada a coordenar o núcleo de extensão e então desenvolvemos o projeto para as ações no Parque Botânico, que existem desde o último trimestre de 2017, contando com a sensibilização e engajamento dos alunos da faculdade como um todo e de todos os cursos, para estimular e interagir com a comunidade, para o incentivo ao lazer, preservação do meio ambiente e bem-estar social. Antes de 2017.2 
aconteciam de forma pontual, mas foi institucionalizado, ganhando uma coordenação e um planejamento mais efetivo, a partir do último trimestre de 2017.'

Pergunta 3 - Como têm se dado as ações?

'Aos domingos, pela manhã, os grupos de alunos inscritos como voluntários, se revezam de acordo com o calendário por eles e coordenação, planejado. As práticas variam desde ações esportivas como aulas de zumba, treinamento funcional, caminhada e outras, até a realização de aferição de pressão arterial, teste glicêmico e índice de massa corpórea.'

Pergunta 4 - Houve evolução nas ações?

'Os projetos ligados ao esporte foram institucionalizados também em 2017, sob a coordenação de um ex-professor do curso de Educação Física. Enquanto professora da disciplina de Responsabilidade Socioambiental, agreguei mais ações, e hoje como Coordenadora de Extensão, mantenho efetivo esse e os demais projetos ligados.'

\section{Pergunta 5 - Quanto tem sido investido?}

'Ao ano, há um investimento em média de $\mathrm{R} \$ 10.000$ (dez mil reais) rateados entre todos os projetos.'

\section{Pergunta 6 - Quais os benefícios resultantes?}

'Em 2018 a Associação Brasileira de mantenedoras de Ensino Superior concedeu a faculdade o selo $2017-2018$ de Instituição Socialmente Responsável, que confere mais visibilidade para a nossa instituição, demonstrando nosso compromisso com a reponsabilidade socioambiental e extensão, bem como, possibilita o principal, que é o desenvolvimento do nosso aluno diante da vivência da educação ambiental e ainda a colaboração, convívio e bem estar social. Temos relatos de alunos e da sociedade civil que comprovam esses benefícios e demonstram o interesse em participar e manterem-se atuantes no dia-a-dia, em casa ou no trabalho, independente das atuais ações e do ambiente da faculdade.'

\section{Pergunta 7 - Quais as principais limitações percebidas?}

'Existem poucas limitações, mas existem. A obtenção de voluntários para o rodízio das ações aos domingos é a maior delas, pois nas ações esportivas que ocorrem no ginásio poliesportivo da faculdade a limitação mais frequente acaba sendo apenas o número de interessados ser maior que as vagas disponíveis, mas para as ações no Parque Botânico, persiste a evasão ao longo do semestre, infelizmente. No início do semestre é maior a adesão, porém no decorrer do semestre há uma queda no número desses voluntários. Infelizmente quando não há disciplina em andamento no semestre, como a disciplina de Responsabilidade Socioambiental por exemplo, é mais difícil o engajamento dos alunos, por isso há a necessidade de haver disciplinas atreladas as ações desenvolvidas nos projetos.'

Diante do relato da professora idealizadora do projeto, e atual Coordenadora de Extensão da IES, pode-se identificar que há uma percepção de que os discentes se sentiram, não só a nível acadêmico, mas também pessoal e profissionalmente, engrandecidos e melhor capacitados, quanto a teoria repassada em sala de aula, uma vez que o desenvolvimento de ações socioambientais em campo, mostrou-se fundamental para a assimilação do conhecimento e no preparo de cidadãos socialmente responsáveis.

\section{CONCLUSÕES}

Dado o exposto, foi possível atingir os objetivos propostos neste trabalho científico, diante da relação entre as ações de intervenção propostas e implantadas, a partir de um projeto de Responsabilidade Socioambiental e o desenvolvimento de uma sociedade interessada em preservar os recursos naturais, uma vez que estes são essenciais para a garantia da qualidade devida desta e das próximas gerações, bem como, traz para os alunos engajados nesse tipo de ação, competências que transcendem a teoria vista em sala de aula.

De modo geral, este relato de experiência pode contribuir com estudo científico a respeito da qualidade do ensino e aprendizagem da Responsabilidade Socioambiental nas IES brasileiras, bem como propagar uma futura pesquisa em entidades acadêmicas também na capital cearense, para que se possa avaliar e concluir de forma mais minuciosa o nível de conhecimento sobre sustentabilidade adquirido durante a graduação, uma vez que esse estudo se fundamenta na percepção de uma colaboradora, que foi não só idealizadora como agente de desenvolvimento da prática estudada aqui. Por fim, expõe-se que esta pesquisa tem o caráter de ser preliminar e, portanto, sugere-se futuros estudos mais profundos. 


\section{REFERÊNCIAS}

BOONE, L. E.; KURTZ, D. L.. Contemporary marketing.

Orlando: The Dryden Press, 2001.

CAIXETA, J. E.; SOUSA, M. A.. Responsabilidade social na educação superior: contribuições da psicologia escolar. Psicol. Esc. Educ., v.17, n.1, p.133-140, 2013.
DIAS SOBRINHO, J.. Educação Superior, globalização e democratização: Qual universidade?. Revista Brasileira de Educação, v.28, p.164-173, 2005.

VASCONCELOS, M. L. M. C.. A formação do professor de 3o grau. São Paulo: Pioneira, 1996.

A CBPC - Companhia Brasileira de Produção Científica (CNPJ: 11.221.422/0001-03) detém os direitos materiais desta publicação. Os direitos referem-se à publicação do trabalho em qualquer parte do mundo, incluindo os direitos às renovações, expansões e disseminações da contribuição, bem como outros direitos subsidiários. Todos os trabalhos publicados eletronicamente poderão posteriormente ser publicados em coletâneas impressas sob coordenação da Sustenere Publishing, da Companhia Brasileira de Produção Científica e seus parceiros autorizados. Os (as) autores (as) preservam os direitos autorais, mas não têm permissão para a publicação da contribuição em outro meio, impresso ou digital, em português ou em tradução. 